\title{
Analisa Usahatani Padi Ciherang dengan Sistem Tanam Jajar Legowo di Kecamatan Sungai Pandan Kabupaten Hulu Sungai Utara
}

\section{(Financial Analysis of Ciherang Rice on Cropping Systems Jajar Legowo in The District of Sungai Pandan Hulu Sungai Utara Regency)}

\author{
Purna Kusumayana $^{1)}$ \& Norma Yunita ${ }^{2)}$ \\ Program Studi Agribisnis, Sekolah Tinggi Ilmu Pertanian Amuntai \\ ${ }^{1)}$ kusumayanapurna@yahoo.com \\ ${ }^{2)}$ normayunita@yahoo.com
}

\begin{abstract}
ABSTRAK
Penelitian ini bertujuan mengetahui: (i) biaya, penerimaan, pendapatan dan keuntungan yang diperoleh dari usaha tani padi Ciherang dengan sistem tanam jajar legowo, (ii) kelayakan usahatani padi ciherang dengan sistem tanam jajar legowo di Kecamatan Sungai Pandan Kabupaten Hulu Sungai Utara. Dalam sistem penanaman jajar legowo, biaya rata-rata total responden untuk musim tanam satu kali di Kabupaten Sungai Pandan adalah Rp 11.332.588,75, - / pertanian. Penerimaan yang didapat rata-rata adalah Rp18.149.982, - / pertanian. dan rata-rata pendapatan usahatani adalah $R p$ 12.717.856,85, - / pertanian, sedangkan rata-rata untung responden petani adalah $R p$ 6.817.393, - / pertanian, laba yang diperoleh petani setiap kilogram responden adalah $R p$ 1.714, / pertanian. Kelayakan rata-rata dalam usahatani padi sistem pertanaman Ciherang jajar legowo di Kecamatan Sungai Pandan. di pertanian padi sistem pertanaman Ciherang, jajar legowo. Dalam sistem rata-rata kelayakan jajar legowo pada usahatani padi Ciherang yang diterima petani adalah untuk petani sebesar 1,61 / usahatani yang berarti usaha tani sepadan dengan usaha.
\end{abstract}

Kata kunci : Biaya, produksi, penerimaan, laba, kelayakan.

\begin{abstract}
This Research aims to determine the cost of production, receipts, revenues, profits and determine the feasibility. The research was conducted in the District of Sungai Pandan Hulu Sungai Utara Regency Province South Kalimantan. In system planting of jajar legowo, the average cost of total respondents for one-time farmer planting season in the District of Sungai Pandan is Rp 11.332.588,75,- /farming. Receipts obtained average is $R p$ 18.149.982,- /farming. and the average farm income is $R p$ 12.717.856,85,/farming, while the average profit farm farmer respondent was $R p$ 6.817.393,-/farming, profits obtained by farmers every kilograms respondent was $R p$ 1.714, /farming. Feasibility average in rice farming of Ciherang cropping systems jajar legowo in the District of Sungai Pandan. in rice farming of Ciherang cropping systems jajar legowo. In the system of jajar legowo feasibility averages on rice farming Ciherang received by farmers is for farmers is 1,61/farming meaning that farming is worth the effort.
\end{abstract}

Keywords: Cost, production, revenue, profit, feasibility.

\section{PENDAHULUAN}

Tanaman pangan khususnya padi masih menjadi komoditas utama rakyat Indonesia, sehingga pemerintah terus mendorong upaya peningkatan produksi padi nasional melalui berbagai program. Dilain pihak isu terjadinya penurunan luas tanam oleh kegiatan konversi lahan untuk non pertanian atau bahkan oleh komoditas non padi, terjadinya el-nino, dan penggunaan benih tidak berlabel telah menjadi perhatian serius karena dikhawatirkan dapat menurunkan produksi yang ditentukan (BPTP Kalimantan Selatan, 2003).

Kabupaten Hulu Sungai Utara merupakan penghasil pangan terutama padi yang menjadi perhatian serius setiap tahunnya untuk memenuhi kebutuhan pangan masyarakatnya.

Salah satu tujuan utama kegiatan usahatani adalah untuk mendapatkan atau memperoleh pendapatan bersih setinggitingginya. Pendapatan bersih suatu usahatani sangat ditentukan oleh tiga faktor yaitu jumlah hasil per hektar, harga hasil per unit 
dan biaya yang dikeluarkan selama proses produksi (Mubyarto, 1989).

Teknologi sistem tanam jajar legowo dan penggunaan varietas unggul yaitu Ciherang adalah salah satu penerapan teknologi di Kecamatan Sungai Pandan yang memiliki prospek cukup besar untuk diterapkan, namun belum diketahui tingkat pendapatan, penerimaan, keuntungan, dan kelayakan yang diterima petani.

Penelitian ini bertujuan mengetahui: (i) biaya, penerimaan, pendapatan dan keuntungan yang diperoleh dari usaha tani padi Ciherang dengan sistem tanam jajar legowo, (ii) kelayakan usahatani padi ciherang dengan sistem tanam jajar legowo di Kecamatan Sungai Pandan Kabupaten Hulu Sungai Utara.

\section{METODE PENELITIAN}

\section{Lokasi dan Waktu Penelitian}

Penelitian ini dilakukan di Kecamatan Sungai Pandan, Kabupaten Hulu Sungai Utara yang dimulai dari bulan Juni September 2015.

\section{Jenis dan Sumber Data}

Jenis penelitian ini menggunakan sumber-sumber dari data primer dan sekunder. Data primer akan diperoleh melalui wawancara langsung dengan petani. Sedangkan data sekunder diperoleh dari dinas atau instansi terkait yang ada keterkaitannya dengan penelitian ini (Umar, 2006).

\section{Metode Pengumpulan Data}

Metode yang digunakan dalam penelitian ini adalah proporsive sampling yaitu cara pengambilan sampel dengan menetapkan ciri yang sesuai tujuan (Nazir, 1983). Responden adalah anggota kelompok tani yang diambil dari 4 (empat) desa yaitu dengan produktivitas tertinggi di Kecamatan Sungai Pandan yang menggunakan varietas ciherang dengan penerapan sistem tanam jajar legowo.

\section{Analisis Data}

Untuk mengetahui tujuan pertama yaitu besarnya biaya produksi digunakan perhitungan biaya eksplisit dan implisit dengan rumus :

$$
\mathrm{TC}=\mathrm{TCe}+\mathrm{TCi}
$$

dimana:

$\mathrm{TC}=$ Biaya total $(\mathrm{Rp} / \mathrm{musim}$ tanam $)$

$\mathrm{TCe}=$ Biaya eksplisit total $(\mathrm{Rp} / \mathrm{musim}$ tanam)

$\mathrm{TC}$ = Biaya implisit total $(\mathrm{Rp} / \mathrm{musim}$ tanam)

Rumus yang digunakan untuk menghitung biaya eksplisit adalah sebagai berikut :

$$
\begin{aligned}
& \text { TCe }=\text { Xei . Pxei } \\
& \text { dimana : } \\
& \mathrm{TCe}=\text { Biaya aksplisit }(\mathrm{Rp} / \mathrm{musim} \text { tanam }) \\
& \text { Xei = Jumlah input/faktor produksi } \\
& \text { eksplisit ke-i } \\
& \text { Pxei }=\text { Harga per unit input eksplisit } \\
& \text { ke-i (Rp/unit) } \\
& \mathrm{i} \quad=1,2,3 \ldots \ldots \ldots \ldots . \mathrm{n}
\end{aligned}
$$

Untuk menghitung biaya implisit digunakan rumus sebagai berikut :

$$
\mathrm{TCi}=\mathrm{Xii}-\text { Pxii }
$$

dimana :

$\mathrm{TCi}=$ Biaya implisit $(\mathrm{Rp} / \mathrm{musim}$ tanam $)$

$\mathrm{Xii}=$ Jumlah input/faktor produksi implisit ke-i

Pxii $=$ harga per unit input implisit ke-i (Rp/unit)

$\mathrm{i} \quad=1,2,3 \ldots \ldots \ldots \ldots . \mathrm{n}$

Sedangkan untuk mengetahui penerimaan usahatani digunakan rumus sebagai berikut :

dimana :

$$
\mathrm{TR}=\mathrm{Y} . \mathrm{Py}
$$

$\mathrm{TR}=$ Penerimaan total (total revenue)

$\mathrm{Y}=$ Produksi $(\mathrm{kg})$

$\mathrm{Py} \quad=$ Harga gabah $(\mathrm{Rp} / \mathrm{kg})$

Pendapatan usaha tani dihitung dengan menggunakan rumus sebagai berikut :

$$
\mathrm{FI}=\mathrm{TR}-\mathrm{TCe}
$$

dimana :

FI $=$ Pendapatan petani $(\mathrm{Rp} / \mathrm{musim}$ tanam)

$\mathrm{TR}=$ Penerimaan $(\mathrm{Rp} / \mathrm{musim}$ tanam $)$

$\mathrm{TCe}=$ Biaya eksplisit (Rp/musim tanam $)$ 
Untuk mengetahui besarnya keuntungan usahatani digunakan rumus sebagai berikut :

dimana :

$$
\pi=\mathrm{TR}-(\mathrm{TCe}+\mathrm{TCi})
$$

$\pi=$ Keuntungan (profit), $(\mathrm{Rp} / \mathrm{musim}$ tanam)

$\mathrm{TR}=$ Penerimaan total (total revenue), (Rp/musim tanam)

$\mathrm{TCe}=$ Biaya eksplisit total $(\mathrm{Rp} / \mathrm{musim}$ tanam)

$\mathrm{TCi}=$ Biaya implisit total $(\mathrm{Rp} /$ musim tanam)

Untuk menghitung penyusutan dapat digunakan rumuskan sebagai berikut :

$$
\mathrm{Du}=\frac{\mathrm{Na}-\mathrm{Ns}}{\mathrm{Up}}
$$

dimana :

$\mathrm{Du}=$ Besarnya nilai penyusutan barang modal tetap selama masa produksi

$\mathrm{Na}=$ Besarnya nilai awal barang modal tetap (Rp)

Ns = Besarnya nilai sisa dari barang modal tetap (Rp)

$\mathrm{U}=$ umur penggunaan barang modal tetap tetap yang bersangkutan

Le = Lamanya penggunaan efektif barang pada suatu usaha tertentu

Tabel 1. Biaya total rata-rata petani responden padi Ciherang pada sistem tanam jajar legowo di Kecamatan Sungai Pandan
Untuk menjawab tujuan kedua yaitu kelayakan usahatani digunakan rumus berikut :

$$
\mathrm{RCR}=\frac{\mathrm{TR}}{-----}
$$

dimana :

$\mathrm{RCR}=$ Revenue Cost Ratio

$\mathrm{TR}=$ Penerimaan total (total revenue), (Rp/musim tanam)

$\mathrm{TC}=$ Biaya total (total cost), $(\mathrm{Rp} / \mathrm{musim}$ tanam)

Apabila nilai RCR lebih besar dari pada satu (RCR > 1) maka usaha tersebut layak diusahakan. Sebaliknya apabila nilai RCR kurang dari satu $(\mathrm{RCR}<1)$ maka usaha tersebut tidak layak untuk diteruskan (Soekartawi, 1994).

\section{HASIL DAN PEMBAHASAN}

\section{Biaya Total}

Dalam perhitungan usahatani padi Ciherang ini biaya total merupakan penjumlahan dari biaya eksplisit dan biaya implisit. Rincian biaya total rata-rata padi Ciherang pada sistem tanam jajar legowo dapat dilihat pada Tabel 1.

\begin{tabular}{clcc}
\hline No & \multicolumn{1}{c}{ Uraian Biaya } & Jumlah Biaya (Rp) & Persentase (\%) \\
\hline 1 & Biaya Implisit & $5.900 .463,75$ & 52,07 \\
2 & Biaya eksplisit & $5.432 .125,00$ & 47,93 \\
\hline \multicolumn{2}{l}{ Jumlah } & $11.332 .588,75$ & 100 \\
\hline
\end{tabular}

Berdasarkan Tabel 1, biaya terbesar yang harus dikeluarkan oleh petani responden pada sistem tanam jajar legowo adalah biaya implisit yaitu Rp 5.900.463,75,/usahatani dengan persentase 52,07\%, sedangkan biaya yang terkecil adalah biaya eksplisit yaitu sebesar Rp 5.432.125,00,/usahatani dengan persentase sebesar $47,93 \%$. Biaya implisit dikeluarkan lebih

Tabel 2. Penerimaan rata-rata petani responden padi Ciherang pada sistem tanam jajar legowo di Kecamatan Sungai Pandan besar karena harga sewa lahan yang cukup mahal sehingga biaya yang dikeluarkan cukup besar.

\section{Penerimaan}

Penerimaan rata-rata petani responden padi Ciherang pada sistem tanam jajar legowo dapat dilihat pada Tabel 2.

\begin{tabular}{lll}
\hline No & Jumlah Produksi $(\mathrm{Kg}) \quad$ Harga $(\mathrm{Rp} / \mathrm{Kg}) \quad$ Jumlah Penerimaan (Rp)
\end{tabular}




\begin{tabular}{llll}
\hline 1 & 3.993 & $4.545,45$ & $18.149 .981,85$ \\
\hline
\end{tabular}

Pendapatan

Tabel 3. Pendapatan rata-rata petani responden padi Ciherang pada sistem tanam jajar legowo di Kecamatan Sungai Pandan

\begin{tabular}{cccc}
\hline No & Penerimaan & Total Biaya Eksplisit & Jumlah Pendapatan (Rp) \\
\hline 1 & $18.149 .981,85$ & 5.432 .125 & $12.717 .856,85$ \\
\hline
\end{tabular}

Berdasarkan Tabel 3 diatas, jumlah pendapatan rata-rata petani responden padi Ciherang pada sistem jajar legowo sebesar Rp. 12.717.856,85,-/usahatani.

Pendapatan dapat diperoleh lebih besar apabila petani mampu meningkatkan penerimaan dan menekan biaya eksplisit seperti efesiensi tenaga kerja, pembelian sarana produksi yang murah dan berkualitas serta masa penggunaan alat dan perlengkapan
Pendapatan rata-rata petani responden pada sistem tanam jajar legowo dapat dilihat pada Tabel 3.

Tabel 4. Perhitungan rata-rata keuntungan petani responden padi Ciherang pada sistem tanam jajar legowo di Kecamatan Sungai Pandan

\begin{tabular}{ccccc}
\hline No & Penerimaan & Biaya Total & Keuntungan $(\mathrm{Rp})$ & Keuntungan $(\mathrm{Kg})$ \\
\hline 1 & 18.149 .982 & $11.332 .588,75$ & 6.817 .393 & 1.714 \\
\hline
\end{tabular}

Dari tabel diatas terlihat bahwa besarnya keuntungan rata-rata yang diterima petani responden adalah sebesar $\mathrm{Rp}$ 6.817.393,/usahatani, sedangkan keuntungan rata-rata setiap kilogram yang diterima petani adalah sebesar Rp 1.714,-/kg. Keuntungan merupakan indikator atau ukuran bagi keberhasilan pelaksanaan usahatani, banyak faktor yang mempengaruhi keuntungan diantaranya adalah unsur-unsur biaya, penerimaan, pendapatan dan sebagainya. Keuntungan merupakan sumber pendapatan atau barang modal yang relatif lama. Tingginya pendapatan yang diperoleh petani akan memudahkan petani dalam memenuhi kebutuhan hidupnya dan secara tidak langsung akan mensejahterakan kehidupan petani.

\section{Keuntungan}

Perhitungan rata-rata keuntungan dapat dilihat pada Tabel 4. bagi usahatani karena keuntungan adalah imbalan yang diterima petani atas biayabiaya yang dikeluarkannya selama pelaksanaan usahatani. Makin besar keuntungan makin berhasil pula petani dalam mengelola usahataninya.

\section{Kelayakan (Reveneu Cost Ratio/RCR)}

Perhitungan kelayakan usahatani padi ciherang dengan sistem tanam jajar legowo adalah sebagai berikut :

Tabel 4. Kelayakan usahatani padi ciherang dengan sistem tanam jajar legowo di Kecamatan Sungai Pandan

\begin{tabular}{cccc}
\hline No & Penerimaan $(\mathrm{Rp})$ & Total Biaya $(\mathrm{Rp})$ & Kelayakan \\
\hline 1 & $18.149 .981,85$ & $11.332 .588,75$ & 1,61 \\
\hline
\end{tabular}

Hasil perhitungan menunjukkan RCR adalah 1,61 artinya usahatani padi ciherang dengan sistem tanam jajar legowo di Kecamatan Sungai Pandan layak usahakan. 


\section{KESIMPULAN}

Biaya total rata-rata petani responden untuk satu kali musim tanam adalah sebesar Rp 11.332.588,75,-/usahatani. Penerimaan rata-rata yang diperoleh adalah sebesar $\mathrm{Rp}$ 18.149.982,-/usahatani dan pendapatan ratarata usahatani adalah sebesar $\mathrm{Rp}$ 12.717.856,85,-/usahatani., sedangkan keuntungan rata-rata usahatani petani responden adalah sebesar $\mathrm{Rp}$ 6.817.393,/usahatani, keuntungan yang didapatkan perkg oleh petani responden adalah sebesar Rp 1.714,/usahatani.

Kelayakan rata-rata pada usahatani padi Ciherang pada sistem tanam jajar legowo di Kecamatan Sungai Pandan sebesar 1,61 yang berarti usahatani pada sistem tanam jajar legowo layak diusahakan.

\section{DAFTAR PUSTAKA}

BPTP Kalimantan Selatan. 2003. Budidaya Padi Rintak di Lahan Lebak. BPTP Kalimantan Selatan. Banjarbaru.

Badan Penelitian dan Pengembangan Pertanian. 2010. Pengelolaan
Tanaman Terpadu (PTT) Padi lahan Rawa Pasang Surut. Badan Penelitian dan Pengembangan Pertanian. Jakarta.

Departemen Pertanian. 1993. Agribisnis, Badan Pendidikan dan Latihan Pertanian. Departemen Pertanian. Jakarta.

Mubyarto. 1989. Pengantar Ekonomi Pertanian. LP3ES. Jakarta.

Nazir, Moh. 1983. Metode Penelitian. Ghalia Indonesia. Jakarta.

Poli Carla. 1992. Pengantar Ilmu Ekonomi. PT Gramedia Pustaka Utama. Jakarta.

Soekartawi. 1994. Teori Ekonomi Produksi Dengan Pokok Bahasan Analisis Fungsi Cobb-Douglas. PT. Raja Grafindo Persada. Jakarta.

Umar, S. 2006. Metodologi Penelitian Untuk Bisnis. Salemba Empat. Jakarta. 